\section{Research article}

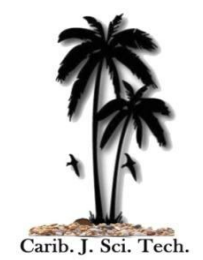

$\underline{\text { Authors \& Affiliation }}$

Sivarama Krishna Reddy V,

V. V. Satyanarayana Peruri*

${ }^{1}$ Department of Chemistry, Acharya

Nagarjuna University, Guntur-522510,

A.P.-India

\section{Corresponding Author}

\section{V. Satyanarayana Peruri}

Email id:

pvvschemistry@gmail.com

vsrkanu@gmail.com

Received $14^{\text {th }}$ October 2019,

Accepted 31 ${ }^{\text {st }}$ December 2019

(C) 2019. The Authors. Published under

Caribbean Journal of Science and Technology

ISSN 0799-3757

\title{
Synthesis of Substituted 1,4-Benzoxazine Derivatives through Diels-Alder Reaction
}

\begin{abstract}
An efficient synthetic protocol is presented for accessing 1,4benzoxazine derivatives from 2-amino phenol derivatives via o-benzoquinones. The key step involves the Diels-Alder reaction between highly reactive $o$ quinone monoimine with butyl vinyl ether/thioether to generate various benzoquinone derivatives.
\end{abstract}

Keywords: 1,4-Benzoxazine, $o$-Quinonemonoimine, o-Benzoquinones, 2Amino phenol, Diels-Alder reaction.

\section{Introduction}

The construction of 1,4-benzoxazines derivatives is a challenging problem that has seen an explosion of interest from the organic synthesis as well as medicinal chemistry programs. 1,4-benzoxazines derivatives are pharmacologically very important molecules due to their numerous biological activities such as anti-depressants ${ }^{1}$, antipsychotic agents ${ }^{2-3}$, cardio vascular ${ }^{4}$, antagonists $^{5}$, anti diabetic ${ }^{6}$, antibacterial ${ }^{7}$.

$o$-Aza quinones are electron-deficient in nature, therefore they react with a variety of nucleophiles and produce different compounds. Among them, one of the most important reactions is the inverse electron demand Diels-Alder (IEDDA) reaction in which these intermediates can act as hetero dienes and react with electron-rich dienophiles.

$o$-Quinone mono-imides and $o$-quinone mono-imines being electrondeficient react with electron-rich species. These reactive intermediates participate as hetero dienes in inverse electron demand Diels-Alder (IEDDA) reaction with electron-rich dienophiles. Heine et al. showed that obenzoquinone mono-imides are willing partners in hetero Diels-Alder reaction by introducing amide functionality and two chlorine atoms on the ring. Nicolaou and his co-workers ${ }^{8-9}$ synthesized $N$-acetyl-o-azaquinones through oxidative dearomatization of different anilides by using DMP and carried out Diels-Alder cycloaddition with vinyl ethers. Recently Fleury discovered an electrochemical method for the generation of $o$-benzoquinone mono-imines, where these reactive species oxidize primary aliphatic amines into enamines to Diels-Alder reaction ${ }^{10-11}$. 
In 2012, Peddinti ${ }^{12-14}$ et al reported a novel method for the chemical generation of o-quinone monoimines, which underwent [4 +2] cycloaddition reaction with vinyl ethers and phenyl vinyl sulfide with complete regioselectivity, to afford $\mathrm{N}$-unsubstituted- 1,4-benzoxazine derivatives of diverse functionalities. Further, they significantly discovered that the incorporation of electron-withdrawing substituent on the aryl ring disfavoured the polymerization and allow for the described intermolecular reaction to proceed.

Thus as part of a research programme towards heterocyclic synthesis, here the author developed this strategy for the generation of $o$-quinone mono imides as electrophilic reagents by oxidative dearomatization of $o$ amidophenols $\mathbf{1}$. The objectives of the present study are to investigate a) chemical generation of $o$-quinone monoimides (o-QMIs) 1 by using less expensive hypervalent iodine reagents [phenyliodoniumtrifluoroacetate (PIFA)], b) reactivity of $o$-quinone monoimides 2 towards Diels-Alder reaction, c) Synthesis of benzoxazine derivatives.

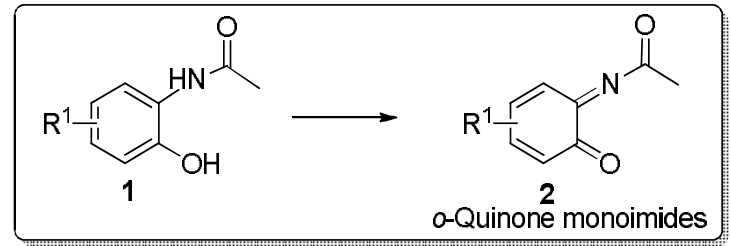

\section{Materials and methods}

\section{General remarks}

The reactions associated with the formation of gasses and application of heat were performed in a wellventilated hood for safety reasons. Moisture sensitive reactions were carried out by using a guard tube filled with either blue silica gel or calcium chloride. Reagents and solvents were transferred under nitrogen using syringes or cannulae as and when added. All solvents were dried and purified according to standard techniques by using $\mathrm{P}_{2} \mathrm{O}_{5}$, $\mathrm{CaH}_{2}$, Na metal.

The chemicals were purchased from the companies Sigma-Aldrich, Across, Avra, Hi-media, S. D. Fine chemicals and were used as received unless otherwise stated.

\section{Instrumentation}

${ }^{1} \mathrm{H}-\mathrm{NMR}$ spectra were recorded on Brüker AMX-500 instrument (500 MHz). Chemical shifts are given in ppm relative to tetramethylsilane $(\delta 0.00)$. Solvent residual peaks $\left(\mathrm{CDCl}_{3}, \delta 7.26 \mathrm{ppm} ; \mathrm{DMSO}, \delta 2.50 \mathrm{ppm} ;\right)$ were used as internal standards. ${ }^{13} \mathrm{C}$ NMR spectra were recorded on Bruker 500 spectrometer $(125 \mathrm{MHz})$. Chemical shifts are given in ppm and were determined by comparison with solvent peaks $\left(\mathrm{CDCl}_{3}, \delta 77.0 \mathrm{ppm}\right.$; DMSO, $\left.\delta 39.5 \mathrm{ppm}\right)$. IR spectra were measured on a Perkin-Elmer spectrometer as $\mathrm{KBr}$ pellets or neat (in case of liquid compounds). Only characteristic absorption bands were reported. Absorptions are given in wavenumbers $\left(\mathrm{cm}^{-1}\right)$. High-resolution mass spectra (HRMS) were recorded on Waters-HAB213, microTOF-Q II-10262 and Jeol JMS600H spectrometers. Melting points were measured in open glass capillaries with Perfit apparatus and are uncorrected.

Purification by gravity column chromatography was carried out on a glass column (10-50 mm diameter) using silica gel with 100-200 mesh or silica gel neutralized with triethylamine of the same mesh. All reactions were monitored by using TLC aluminium sheets of silica gel $60 \mathrm{~F}_{24}$ (Merck) with a fluorescent indicator and $\mathrm{KMnO}_{4}$ stain.

\section{Synthetic Procedures}

\section{General procedure for the synthesis of benzoxazine derivatives}


A solution of phenyliodonium trifluoroacetate (PIFA) (1.2 equiv.) in dichloromethane (2 mL) was added drop-wise to $o$-aminophenol (1a-1h, $1 \mathrm{mmol})$ and alkyl vinyl ether $(\mathbf{3 a} / \mathbf{3 b}, 5 \mathrm{mmol})$ or phenyl vinyl sulphide/dihydrofuran/dihydropyran $(\mathbf{5 / 6 / 7}, 2 \mathrm{mmol})$ in dichloromethane $(6 \mathrm{~mL})$ at $0{ }^{\circ} \mathrm{C}$. The reaction mixture was stirred at the same temperature. After completion of the reaction (based on TLC analysis) the solvent was removed under reduced pressure and the crude reaction mixture was loaded directly on the silica gel column. The product was eluted by using ethyl acetate in hexanes (2:8) for compounds $\mathbf{4 b - 4 e 1 . ~}$

2-Butyloxy-3,4-dihydro-7-nitro-2H-1,4-benzoxazine (4b): Reaction time: 3 h.; Yield: 68\% as yellow solid; MP: 62-63 ${ }^{\circ} \mathrm{C}$; IR (film) v vax: 3324, 3050, 2947, 1669, 1602, 1288, $834 \mathrm{~cm}^{-1}$.; ${ }^{1} \mathbf{H}$ NMR $\left(\mathbf{C D C l}_{3}, \mathbf{5 0 0}\right.$ MHz): $\delta 7.77(\mathrm{dd}, J=2.5,8.5 \mathrm{~Hz}, 1 \mathrm{H}), 7.72(\mathrm{~d}, J=2.5 \mathrm{~Hz}, 1 \mathrm{H}), 6.53(\mathrm{~d}, J=8.5 \mathrm{~Hz}, 1 \mathrm{H}), 5.27(\mathrm{t}, J=2.0 \mathrm{~Hz}, 1 \mathrm{H})$, 4.53 (brs, $1 \mathrm{H}), 3.85(\mathrm{td}, J=3.0,6.5 \mathrm{~Hz}, 1 \mathrm{H}), 3.62(\mathrm{td}, J=3.0,6.5 \mathrm{~Hz} 1 \mathrm{H}), 3.52(\mathrm{td}, J=2.5,12.5 \mathrm{~Hz}, 1 \mathrm{H}), 3.47(\mathrm{qd}$, $J=2.0,12.0 \mathrm{~Hz}, 1 \mathrm{H}), 1.56-1.51(\mathrm{~m}, 2 \mathrm{H}), 1.31-1.24(\mathrm{~m}, 2 \mathrm{H}), 0.86(\mathrm{t}, J=7.5 \mathrm{~Hz}, 3 \mathrm{H}) \mathrm{ppm} . ;{ }^{13} \mathbf{C} \mathbf{N M R}(\mathbf{C D C l}, \mathbf{1 2 5}$ MHz): $\delta 140.1(C), 138.9(C), 138.4(C), 119.3(C H), 113.5(C H), 112.5(C H), 93.7(C H), 68.3\left(C_{2}\right), 44.2\left(C H_{2}\right)$, $31.3\left(\mathrm{CH}_{2}\right), 19.0\left(\mathrm{CH}_{2}\right), 13.6\left(\mathrm{CH}_{3}\right)$ ppm.; HRMS (ES+): $m / z$ calcd for $\mathrm{C}_{12} \mathrm{H}_{16} \mathrm{~N}_{2} \mathrm{O}_{4}[\mathrm{M}+\mathrm{Na}]^{+}:$275.1008, found 275.1002 .

3,4-Dihydro-2-ethoxy-7-nitro-2H-1,4-benzoxazine (4c): Reaction time: 2 h.; Yield: $72 \%$ as yellow oily liquid.; IR (film) vmax: 3386, 3080, 2963, 1664, 1599, 1269, $967 \mathrm{~cm}^{-1}$.; ${ }^{1} \mathbf{H}$ NMR (CDCl, 500 MHz): $\delta 7.71(\mathrm{dd}, J$ $=2.5,9.0 \mathrm{~Hz}, 1 \mathrm{H}), 7.66(\mathrm{~d}, J=2.5 \mathrm{~Hz}, 1 \mathrm{H}), 6.52(\mathrm{~d}, J=9.0 \mathrm{~Hz}, 1 \mathrm{H}), 5.25(\mathrm{t}, J=2.0 \mathrm{~Hz}, 1 \mathrm{H}), 4.93(\mathrm{brs}, 1 \mathrm{H}), 3.87$ $(\mathrm{dq}, J=3.0,7.0 \mathrm{~Hz}, 1 \mathrm{H}), 3.67(\mathrm{dq}, J=2.5,7.0 \mathrm{~Hz}, 1 \mathrm{H}), 3.49(\mathrm{dt}, J=2.0,14.5 \mathrm{~Hz}, 1 \mathrm{H}), 3.43(\mathrm{dq}, J=2.5,14.0 \mathrm{~Hz}$, 1H), $1.17(\mathrm{t}, J=7.0 \mathrm{~Hz}, 3 \mathrm{H})$ ppm.; ${ }^{13} \mathbf{C}$ NMR (CDCl3, 125 MHz): $\delta 140.3(C), 138.7(C), 138.1(C), 119.3(C H)$, $113.3(\mathrm{CH}), 112.4(\mathrm{CH}), 93.5(\mathrm{CH}), 64.1\left(\mathrm{CH}_{2}\right), 44.0\left(\mathrm{CH}_{2}\right), 14.8\left(\mathrm{CH}_{3}\right)$ ppm.; HRMS (ES+): $m / z$ Calcd. for $\mathrm{C}_{10} \mathrm{H}_{12} \mathrm{~N}_{2} \mathrm{O}_{4}[\mathrm{M}+\mathrm{Na}]^{+}:$247.0695, found 247.0699.

3,4-Dihydro-7-nitro-2-phenylthio-2H-1,4-benzoxazine (4d): Reaction time: 4 h.; Yield: $61 \%$ as yellow oily liquid.; IR (film) vmax: 3382, 3021, 2804, 1610, 1517, $708 \mathrm{~cm}^{-1}$.; ${ }^{\mathbf{1}} \mathbf{H} \mathbf{~ N M R}\left(\mathbf{C D C l}_{\mathbf{3}}, \mathbf{5 0 0} \mathbf{M H z}\right): \delta 7.81(\mathrm{dd}, J=$ 2.5, 9.0 Hz, 1H), $7.75(\mathrm{~d}, J=2.5 \mathrm{~Hz}, 1 \mathrm{H}), 7.53-7.52(\mathrm{~m}, 2 \mathrm{H}), 7.37-7.33(\mathrm{~m}, 3 \mathrm{H}), 6.61(\mathrm{~d}, J=9.0 \mathrm{~Hz}, 1 \mathrm{H}), 5.69(\mathrm{t}, J$ $=3.0 \mathrm{~Hz}, 1 \mathrm{H}), 4.68(\mathrm{br}, 1 \mathrm{H}), 3.86(\mathrm{dd}, J=3.0,12.0 \mathrm{~Hz}, 1 \mathrm{H}), 3.66(\mathrm{dt}, J=3.0,3.0 \mathrm{~Hz}, 1 \mathrm{H}) \mathrm{ppm}$; ${ }^{13} \mathbf{C ~ N M R}_{(\mathbf{C D C l}}$, 125 MHz): $\delta 139.5(C), 139.2(C), 139.1(C), 132.6(C), 132.5(C H), 129.2(C H), 128.2(C H), 119.6(C H), 114.2$ $(C H), 113.1(C H), 80.8(C H), 45.7\left(C_{2}\right)$ ppm.; HRMS (ES+): $m / z$ calcd for $\mathrm{C}_{14} \mathrm{H}_{12} \mathrm{~N}_{2} \mathrm{O}_{3} \mathrm{~S}[\mathrm{M}+\mathrm{Na}]^{+}: 311.0467$, found 311.0468 .

7-Nitro-2,3,3a,9a-tetrahydro-4H-furo[2,3-b][1,4]benzoxazine (4e): Reaction time: $0.5 \mathrm{~h}$.; Yield: $68 \%$ as yellow solid.; MP: $86-87^{\circ} \mathrm{C}$; IR (film) vmax: 3356, 3051, 2935, 1673, 1600, 1254, $972 \mathrm{~cm}^{-1}$.; ${ }^{\mathbf{1}} \mathbf{H}$ NMR (DMSO-d6, $500 \mathrm{MHz}): \delta 6.26(\mathrm{dd}, J=2.5,8.5 \mathrm{~Hz}, 1 \mathrm{H}), 6.07(\mathrm{~d}, J=2.5 \mathrm{~Hz}, 1 \mathrm{H}), 5.23(\mathrm{~d}, J=9.0 \mathrm{~Hz}, 1 \mathrm{H}), 3.90(\mathrm{~d}, J=3.5 \mathrm{~Hz}$, 1H), 2.67-2.59 (m, 2H), 2.52-2.49 (m, 1H), 1.86-1.80 (m, 1H), 1.32-1.25 (m, 1H) ppm.; ${ }^{13}$ C NMR (DMSO-d 6 , 125 MHz): $\delta 140.6(C), 138.9(C), 136.4(C), 120.2(C H), 112.5(C H), 112.0(C H), 96.1(C H), 67.7\left(C H_{2}\right), 52.9(C H)$, $30.5\left(\mathrm{CH}_{2}\right)$ ppm.; HRMS (ES+): $m / z$ calcd for $\mathrm{C}_{10} \mathrm{H}_{10} \mathrm{~N}_{2} \mathrm{O}_{4}[\mathrm{M}+\mathrm{Na}]^{+}: 245.0539$, found 245.0537.

\section{Results and Discussion}

\section{Diels-Alder reaction between o-QMIs and vinyl ethers}

In the initial experiments began with 2-amido-5-methyl phenol, (1a) was stirred with commercially available phenyl iodonium trifluoroacetate (PIFA) in the presence of butyl vinyl ether (3a) in dichloromethane at room temperature (Scheme 1). It was observed that the reaction mixture changed from light brown solution to wine red solution and then immediately it was turned into a black solution. The reaction mixture was analysed with the help of thin-layer chromatography (TLC) and it shows neither benzoxazine product 4 a nor precursor aminophenol 1a (i.e. no identifiable spots on the TLC). After seeing these results, the reaction at a higher temperature has performed but results were disappointed i.e. the above same results were obtained. 
<smiles>Cc1ccc(NCCl)c(O)c1</smiles>

$1 a$

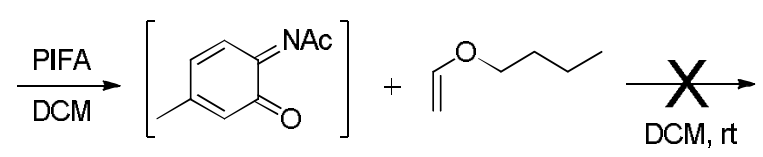

$2 a$
$3 a$<smiles>CCCCOC1CN(C)c2ccc(C)cc2O1</smiles>

$4 a$

Scheme 1: Reaction between amidophenol and butyl vinyl ether

Based on these results and colour observed in the reaction mixture; it was hypothesized that the intermediate $o$-quinone monoimide 2a was formed but the formed intermediate was unable to undergo the Diels-Alder reaction with the dienophile butyl vinyl ether (3a) due to lack of sufficient electron-deficient character in the diene intermediate since these intermediates undergo in inverse electron demand Diels-Alder [IEDDA] reaction as electron-deficient hetero dienes. To examine the hypothesis another reaction was performed with 5-nitro-2amidophenol (1b) and carried out the oxidation and Diels-Alder reaction under the same conditions (Scheme 2). To our delight, the analysis of reaction mixture by TLC reveals that there is isolable product on TLC. The product has isolated by silica gel column chromatography in $68 \%$ yield. The structure of the product was confirmed by ${ }^{1} \mathrm{H}$ and ${ }^{13} \mathrm{C}$ NMR spectroscopy and it reveals that the product is a benzoxazine derivative. To achieve the maximum amount of benzoxazine derivative the reaction conditions were optimized.

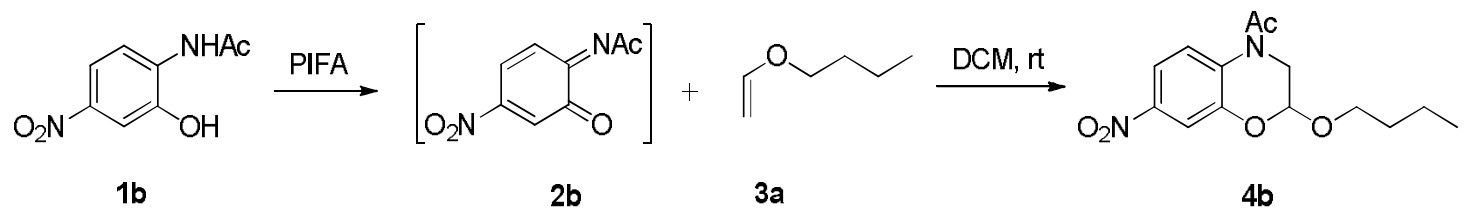

Scheme 2: Reaction of nitroamidophenol with butyl vinyl ether

To extend the scope of this reaction it was decided to incorporate different electron-withdrawing groups at different positions of amidophenol precursor and thereby reacting with various vinyl ethers. With the set of conditions available in hand, the procedure was extended for the remaining reaction of 5-nitro-2-amidophenol (1b) in the presence of enol ethers like ethyl vinyl ether (3a-3b), phenyl vinyl sulfide (5), dihydrofuran (6) and dihydropyran (7). The reactions with ethyl vinyl ether, phenyl vinyl sulfide and dihydrofuan underwent efficiently at $0{ }^{\circ} \mathrm{C}$ and provided the corresponding benzoxazine derivatives $4 \mathrm{~b}-4 \mathrm{i}$ in good to excellent yield (Table 1). However, the reaction with dihydropyran (6) provided the corresponding benzoxazine derivative $4 \mathrm{f}$ in low yield. This may be due to the half-chair structure of the pyran ring. On the other hand, the reactions of 4-nitro-o-quinone monoimide 2c towards oxidation/Diels-Alder reaction provided the corresponding benzoxazine derivatives in low yield (See Table 1) with enol ether $\mathbf{3 a}$. 


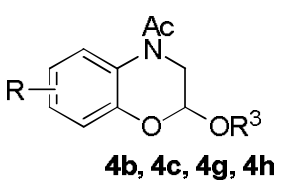

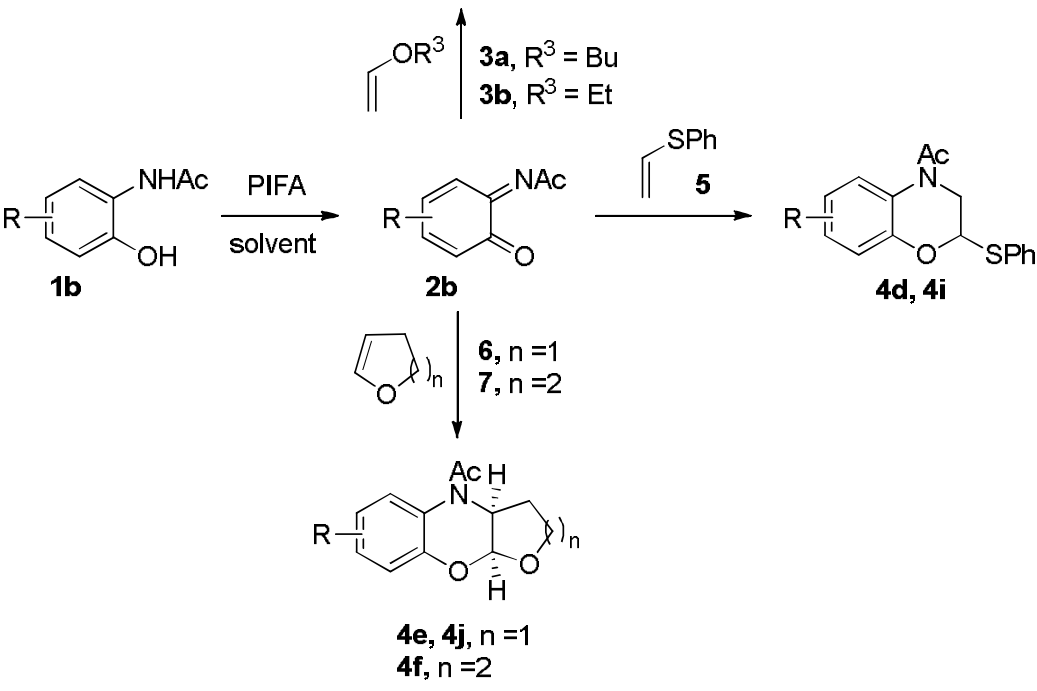

Scheme 3: Oxidation/Diels-Alder reaction of $o$-quinone monoimides with electron-rich olefins

To evaluate this novel methodology, the author screened a variety of amidophenols $\mathbf{1 d - 1 h}$ carrying different electron-withdrawing groups at different positions of the phenyl moiety (Table 2). Since the reaction of 1d with butyl vinyl ether (3a) provided a clean product in the presence of $\mathrm{KHCO}_{3}$, the reactions of $\mathbf{1 d - 1 h}$ with all the enol ethers were performed under the same conditions (Table 2). Although the reactions of amidophenols bearing electron-releasing groups did not work in this procedure therefore it was thought that the evaluating of the nature of the electron-donating group in the presence of the electron-withdrawing group. In this way, methoxy substituent was incorporated in position- 6 of cyano-amidophenol as shown in $\mathbf{1 h}$ and performed oxidation/Diels-Alder reaction. To our surprise, the methoxy group did not show any effect on the reactivity of $\mathbf{2 h}$ and corresponding benzoxazine derivative in good yield as compared to cyano-substituted benzoxazine derivatives (Table2).

The characterization of benzoxazine derivatives has been done on the basis of IR, ${ }^{1} \mathrm{H} N M R,{ }^{13} \mathrm{C}$ NMR and DEPT and mass spectral analysis. The Diles-Alder adducts have displayed IR absorptions at $3050-3062 \mathrm{~cm}^{-1}$ and 1288-1020 $\mathrm{cm}^{-1}$, characteristic absorptions of $\mathrm{C}-\mathrm{H}$ and $\mathrm{C}-\mathrm{O}$ stretching of benzoxazine derivatives. The proton attached at 2-position of benzoxazine derivatives obtained from butyl vinyl ether, ethyl vinyl ether and phenyl vinyl sulfideresonates in the range of $\delta$ 5.75-5.23 and appears as a triplet with coupling constant ${ }^{3} J_{\mathrm{H}}=2.5-3.0 \mathrm{~Hz}$. On the other hand, for the cycloadducts obtained from dihydrofuran and dihydropyran, the acetal proton resonates in the range of $\delta$ 5.37-5.23 and appears as a doublet with a coupling constant ${ }^{3} J_{\mathrm{H}}=4.0-9.0 \mathrm{~Hz}$.

Table 1: Oxidation/Diels-Alder reaction between nitroaminophenols and electron-rich vinyl ethers

\begin{tabular}{|l|c|c|c|c|c|c|c|}
\hline Entry & Aminophenol & $o-Q M I$ & Dienophile & Time (h) & \multicolumn{2}{|c|}{ Product } & Yield (\%) \\
\hline 1 & & & $3 \mathrm{a}$ & 3 &
\end{tabular}




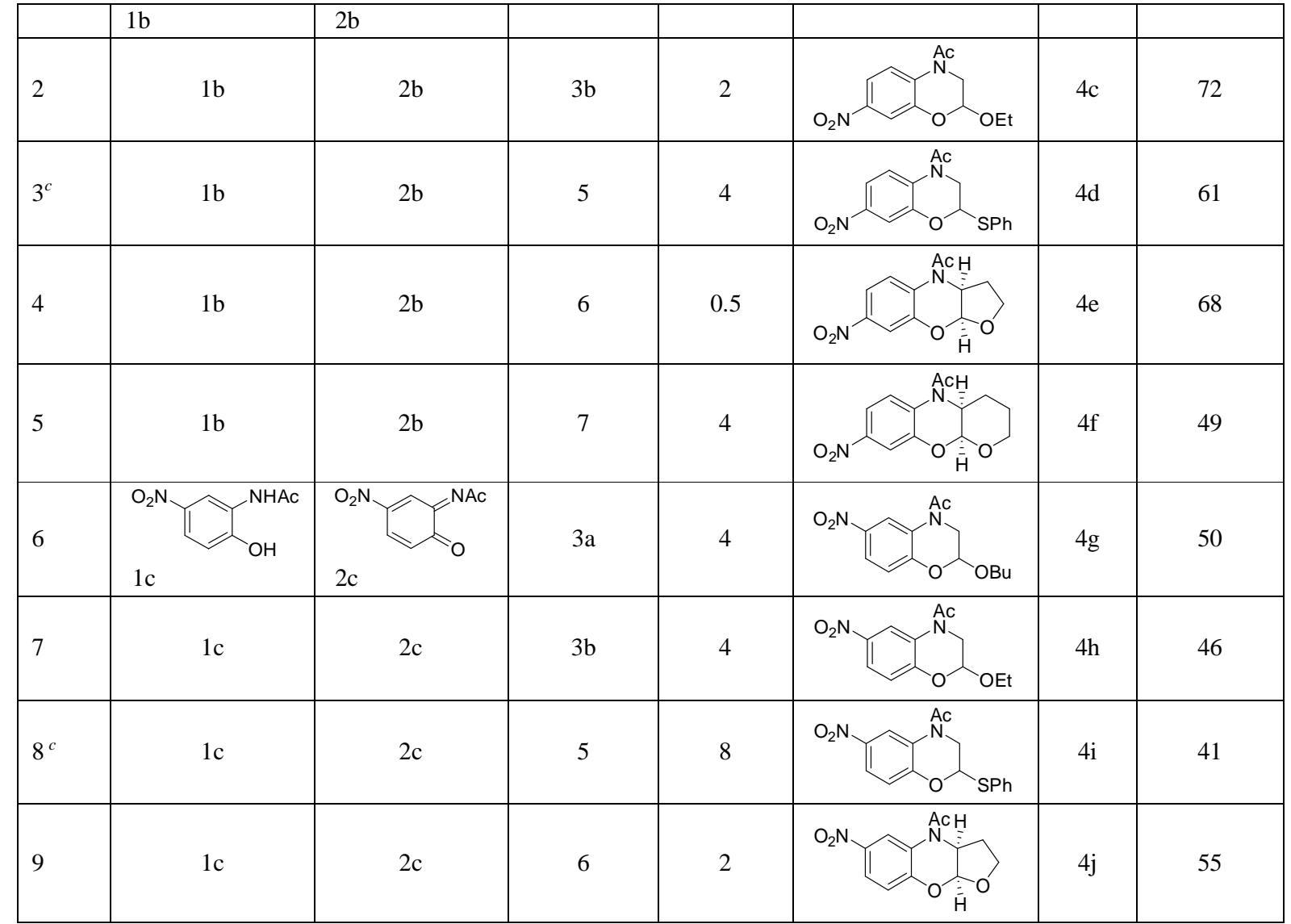

${ }^{a}$ All reactions were carried out with 5 equiv of vinyl ether unless otherwise mentioned.; ${ }^{b}$ Yields of isolated products.

${ }^{c}$ Reaction was carried out with 2 equiv of phenyl vinyl sulfide and slow addition of PIFA.

Table 2: Synthesis of differently substituted 1,4-benzoxazine derivatives. ${ }^{a}$

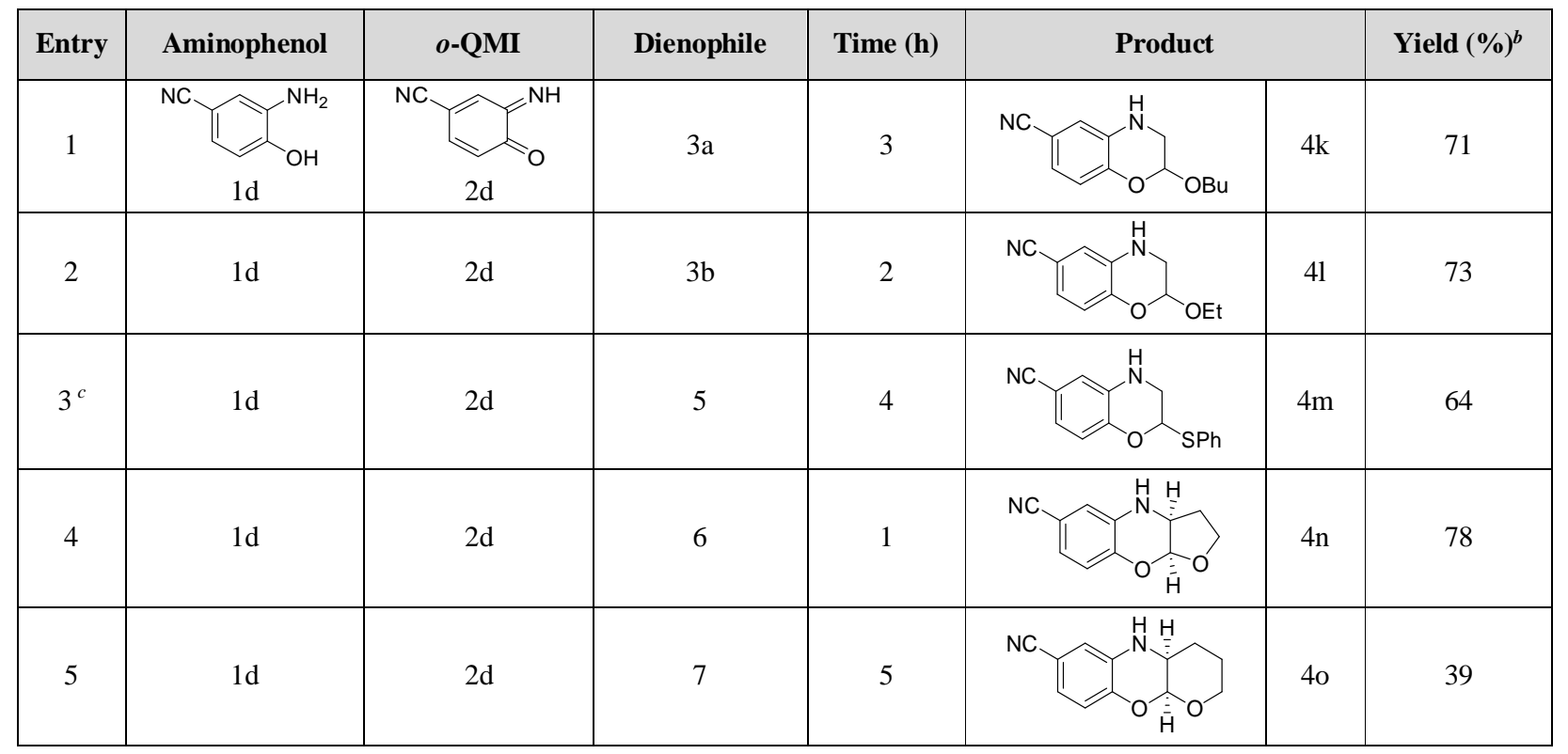


Research article

Sivarama Krishna Reddy et al, Carib. J. Sci. Tech., 2019, 7(1), 88-95

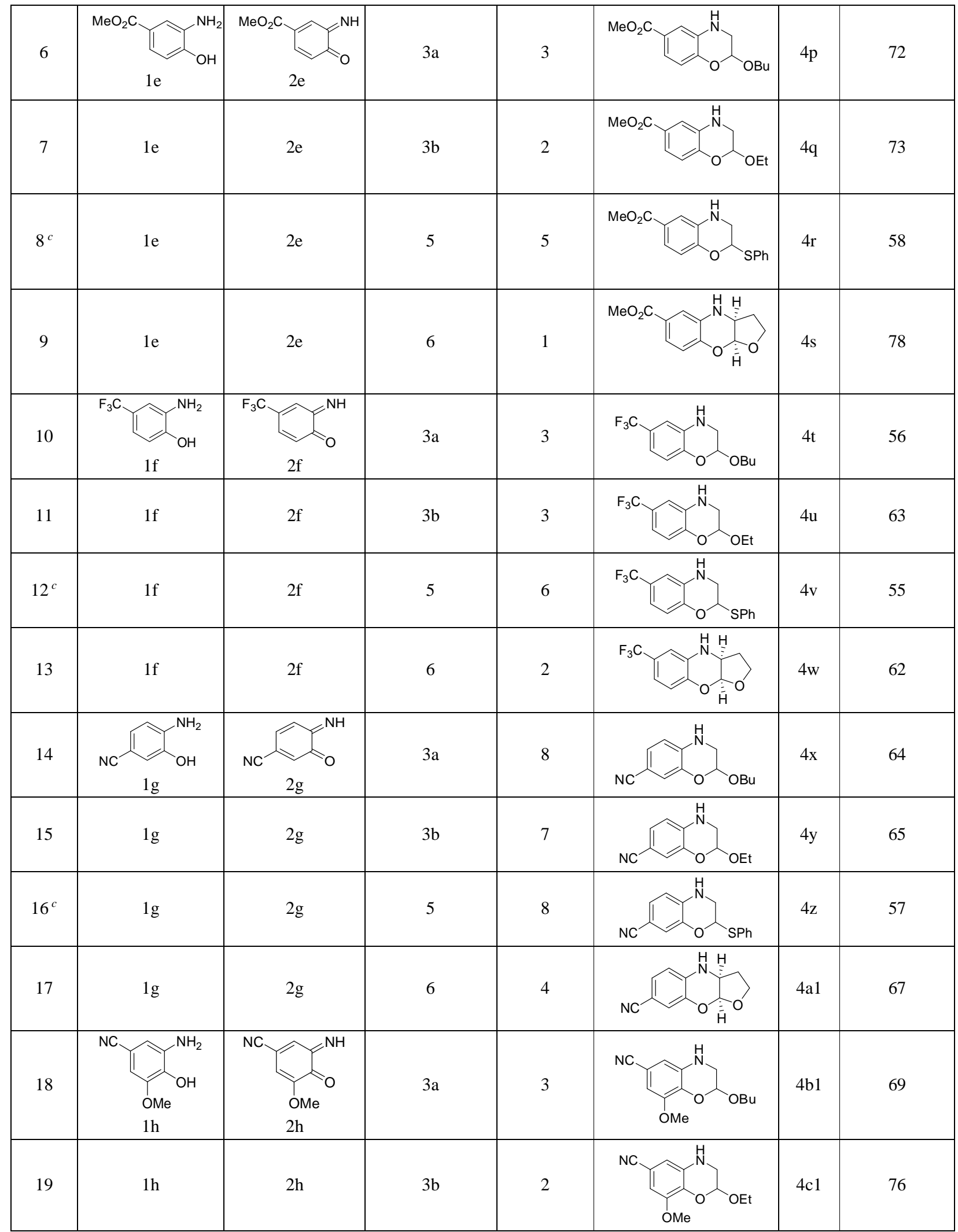




\begin{tabular}{|c|c|c|c|c|c|c|c|}
\hline $20^{c}$ & $1 \mathrm{~h}$ & $2 \mathrm{~h}$ & 5 & 4 & $4 \mathrm{~d} 1$ & 63 \\
\hline 21 & $1 \mathrm{~h}$ & $2 \mathrm{~h}$ & 6 & 1 & 68 \\
\hline
\end{tabular}

${ }^{a}$ All reactions were carried out with 5 equiv of vinyl ether in THF and in presence of $\mathrm{KHCO}_{3}$ unless otherwise mentioned.; ${ }^{b}$ Yield of isolated products. ; ${ }^{c}$ Reaction was carried out with 2 equiv of phenyl vinyl sulfide and slow addition of PIFA in THF and in presence of $\mathrm{KHCO}_{3}$; ${ }^{\text {aC }}$ oupling constants are given in Hertz.

\section{Conclusion:}

In conclusion, we have developed an efficient methodology for the synthesis of 1,4-benzoxazine derivatives by using [4+2] cycloaddition between $o$-quinone monoamine of functionality to generate diverse 1,4benzoxazine derivatives. Based on the results, the method would appear to offer access to most of the 1,4benzoxazine derivatives.

\section{References}

1. Yang. W.; Wang. Y.; Ma. Z.; Golla. R.; Stouch. T.; Seethals. R.; Johonson. S.; Zhou. R.; Gungor. T.; Feyen. J.H.M.; Dickson. J.K.; Bioorg. Med. Chem. Lett. 2004, 14, 2327.

2. Taverne. T.; Diouf. O.; Depreux. P.; Poupaert. J.H.; Lesieur. D.; Lemaitre. B.G.; Renard. P.; Rettori. M.C.; Caignard. D.H.; Pfeiffer. B.; J. Med. Chem. 1998, 41, 2010.

3. Birch. A.M.; Bradley. P.A.; Gill. J.C.; Kerrrigan. F.; Needham. P.L.; J. Med. Chem. 1999, 42, 3342.

4. Largeron. M.; Lockhart. B.; Pfeiffer. B.; Fleury. M.B.; J. Med. Chem. 1999, 42, 5043.

5. Bohme. T.M.; Szafran. C.E.A.; Hallak. H.; Pugsley. T.; Serpa. K.; Schwarz. R.D.; J. Med. Chem. 2002, 45, 3094.

6. Rybczynski. P.J.; Zeck. R.E.; Dudash. J.; Combs. D.W.; Burris. T.P.; Yang.M.; Osborne. M.C.; Chen. X.; Demarest. K.T.; J. Med. Chem. 2004, 47, 196.

7. Mitscccher. L.A.; Sharma. P.N.; Chu. D.T.W.; Shen. L.L.; Pernet. A.G.; J. Med. Chem. 1987, $30,2283$.

8. Nicolaou. K.C.; Mitchell. H.J.; Angew. Chem., Int. Ed. 2001, 40, 207.

9. Nicolaou. K.C.; Mitchell. H.J.; J. Am. Chem. Soc. 2002, 124, 2221.

10. Nogami. T.; Hishida. T.; Yamada. M.; Mikawa. H.; Shirota. Y.; Bull. Chem. Soc. Jpn. 1975, 48, 3709.

11. Hishida. T.; Nogami. T.; Shirota. Y.; Mikawa. H.; Chem. Lett. 1974, 293.

12. Surasani.S.R.; Rajora. V.S.; Bodipati. N.; Peddinti. R.K.; Tetrahedron Lett. 2009, 50, 773.

13. Bodipati. N.; Peddinti. R.K.; Org. Biomol. Chem. 2012, 10, 1958.

14. Bodipati. N.; Peddinti. R.K.; Org. Biomol. Chem. 2012, 10, 4549. 